\title{
ULTRASOUND DIAGNOSIS OF RARE CONGENTIAL ANOMALIES
}

\author{
B. Prathap Kumar ${ }^{1}$
}

\section{HOW TO CITE THIS ARTICLE:}

B. Prathap Kumar. "Ultrasound Diagnosis of Rare Congential Anomalies". Journal of Evolution of Medical and Dental Sciences 2015; Vol. 4, Issue 86, October 26; Page: 15024-15030, DOI: 10.14260/jemds/2015/2132

\begin{abstract}
Patients who came for antenatal scanning have undergone scanning at eight weeks, sixteen weeks and twenty four weeks of pregnancy. Scanning at eight weeks is done to diagnose a pregnancy, =whether pregnancy is intra uterine or extra uterine, =number of gestational sacs, =accurate gestational age determination, =viability of fetus, Scanning at 11-14 weeks is done for both screening and diagnostic purposes. The maximum thickness between the skin and the soft tissue overlying the cervical spine is measured which is called nuchal translucency. Normal nuchal translucency thickness usually increases with gestational age with $1.5 \mathrm{~mm}$ and $2.5 \mathrm{~mm}$ being the $50^{\text {th }}$ and $95^{\text {th }}$ percentile respectively for gestational ages between 10 and 12 weeks. $2.0 \mathrm{~mm}$ and $3.0 \mathrm{~mm}$ are the $50^{\text {th }}$ and $95^{\text {th }}$ percentile respectively for gestational ages between 12 and 14 weeks. An Increased nuchal translucency thickness not only indicates increased suspicion of chromosomal abnormalities but also indicates possibility of multiple structural defects especially of the fetal heart and abdomen. Absence of the nasal bone can be used as a marker for Down syndrome in the first trimester of pregnancy. Inclusion of the nasal bone in the current first-trimester screening protocol along with nuchal translucency, free beta-hCG and PAPP-A can achieve high detection at a very low false-positive rate. Scanning at 18-22 weeks of gestation is done to diagnose fetal anomalies .This is known as TIFFA =TARGETTED IMAGING FOR FETAL ANOMALIES.
\end{abstract}

KEYWORDS: Ultrasound diagnosis of fetal anomalies in utero and termination is such babies thereby reducing fetal morbidity and mortality.

INTRODUCTION: The object of this study is to diagnose fetal anomalies at the earliest and terminating such pregnancies thereby reducing mental trauma to the parents and also reducing the financial burden.

Congenital abnormalities are persistent structural and functional abnormalities that exist at birth. In my professional career I have diagnosed many abnormal fetuses .I would like to share few anomalies.

ANENCEPHALY: Anencephaly is characterized by absence of the cranium along with cerebral hemispheres that are either rudimentary or absent. This anomaly can be diagnosed at 13-14 weeks of gestation.

Anencephaly can be diagnosed on ultrasound by the characteristic absence of brain and bone superior to the orbits.

The case presented here is a couple, consanguineous marriage who delivered an abnormal baby in their first pregnancy, the baby had diastomatomyelia. When the patient was scanned in this (second) pregnancy at $13^{\text {th }}$ week of gestation was diagnosed to have anencephaly. The couple was referred to institute of genetics for genetic evaluation and counseling. 
OMPHALOCELE: Omphalocele is an anterior abdominal wall defect with a covering amnioperitoneal membrane. The herniated organs can be bowel loops, stomach and liver. Most of the omphaloceles contain liver (80\%) and less small bowel and rarely stomach and bladder. Omphaloceles can have associated malformations. They are also associated with fetal chromosomal abnormalities and IUGR.

The following baby was delivered by a consanguineous couple, a primi and the abnormality was diagnosed on tiffa scan.

SPINA BIFIDA AND MENINGOMYELOCELE: Nonunion of vertebral spines with the formation of skin covered sac into which meninges and spinal cord bulge.

This defect involves the vertebral column and spinal cord with disruption of cutaneous and subcutaneous elements as well shown below. The affected vertebras can show a variation contour in comparison with one superior or inferior to it or a U -shaped configurations on transverse scanning.

I have diagnosed many cases of spina bifida and meningomyelocele. The present picture baby is diagnosed in a primi, non-consanguineous couple. This was also diagnosed on tiffa scan.

DIASTOMATOMYELIA: Diastomatomyelia is a rare congenital anomaly where spinal cord is split in longitudinal direction which produces a complete /incomplete sagittal division of spinal cord into two hemi cords.

On ultra sound it appears as a high amplitude central echo running through the spinal canal and widening of posterior ossification centres of the spine.

The case presented here was delivered by a primi, non-consanguineous couple. This abnormality was diagnosed on tiffa scan.

INTESTINAL ATRESIA: The most common cases of intestinal atresia is a vascular incident in utero that Leads to decreased intestinal perfusion and ischemia of the respective segments of the bowel leading to narrowing or complete obliteration of intestinal lumen'.

Antenatal ultrasound shows multiple dilated and fluid filled bowel loops at the proximal stenotic or atretic area. Poly hydramnios is usually present and its severity increases in proximal obstruction. Depending on level of obstruction it can be associated with imperforate anus.

This patient who delivered this baby with intestinal atresia is a fourth gravida, nonconsanguineous couple, who had a third baby with abnormality and was terminated.

CONJOINED TWINS: Conjoined twins is a rare phenomenon ,the occurrence is estimated to range from 1 in 49,000 births to 1 in 1,89,000 births.

Two contradictory theories exist to explain the origin of conjoined twins:

1) The older theory of FISSION, in which the fertilized egg splits partially.

2) FUSION: Here the fertilized egg completely separates, but STEM CELLS find LIKE STEM CELLS on the other twin and fuse the twins together.

I came across only one conjoined twin in my practice till now which I would like to present. This patient, a primi, consanguineous couple came for antenatal checkup on a routine ultrasound at 17 weeks of gestation, I could diagnose that this is a conjoined twin. These twins were fused in chest and abdomen with a single heart. (THORACO- OMPHALOPAGUS) 


\section{ORIGINAL ARTICLE}

Diagnosis of conjoined twins should be suspected whenever mono amniotic monochorionic pregnancy is detected. Sonographic identification of distinct placentae or intervening amniotic membranes rules out fetal conjunction.

The mainstay in prenatal diagnosis of conjoined twins today is use of two dimensional ultrasound enhanced by color flow Doppler at 11-14wks of gestation.

\section{Specific sonographic features indicative of conjoined twins are:}

1) Bifid appearance of fetal pole in first trimester.

2) Absence of separating membranes between fetus.

3) Non separation of fetal bodies, this finding should persist and it should be always visualized at the same anatomic level.

4) Detection of a variety of fetal anomalies.

5) Finding more than three vessels in umbilical cord.

6) Sonographic evidence of fetal heads and bodies lying in the same plane.

7) Unusual extension of the fetal spines.

8) Unusual proximity of fetal extremities.

9) The fetuses do not change position to one another after movement or manipulation or as time passes by.
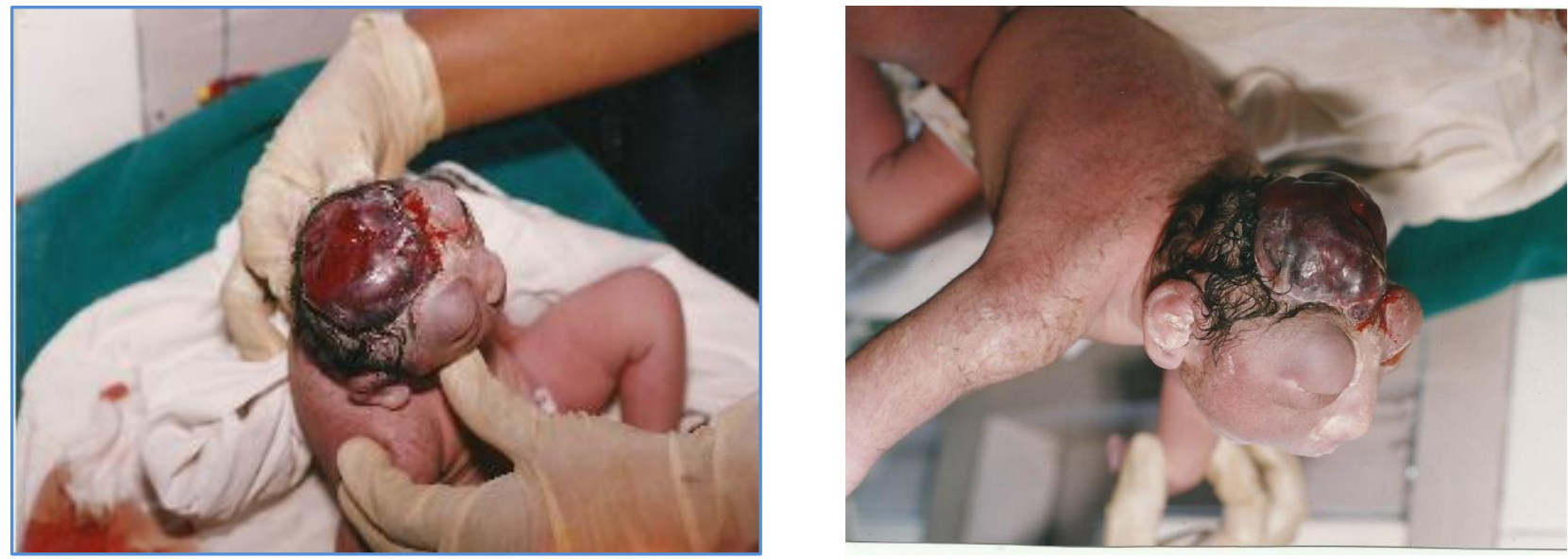

Fig. 1: Anen1

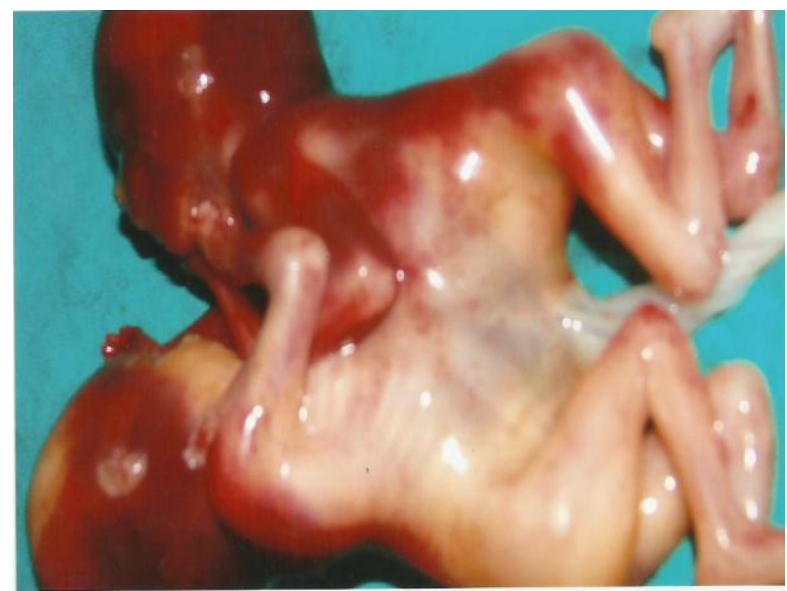

Fig. 2: Conjoint1

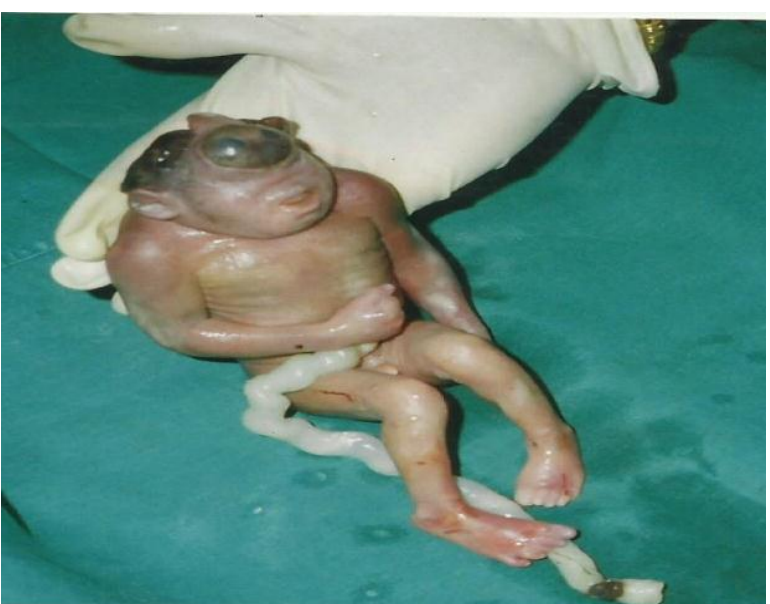

Fig. 2: Cyclops1 


\section{ORIGINAL ARTICLE}

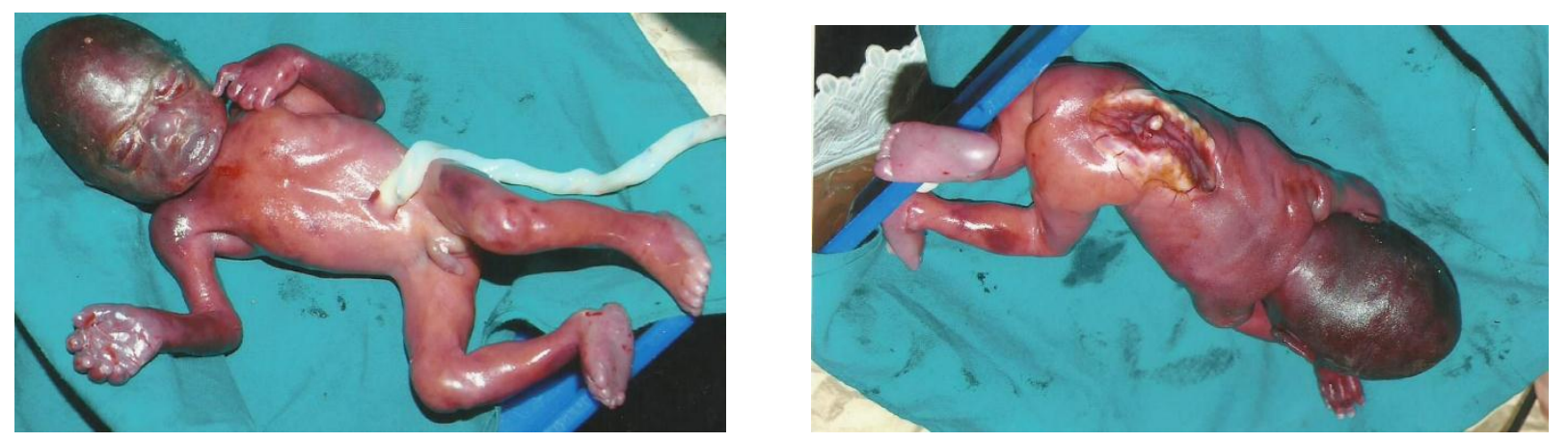

Fig. 3: Diasto mm1
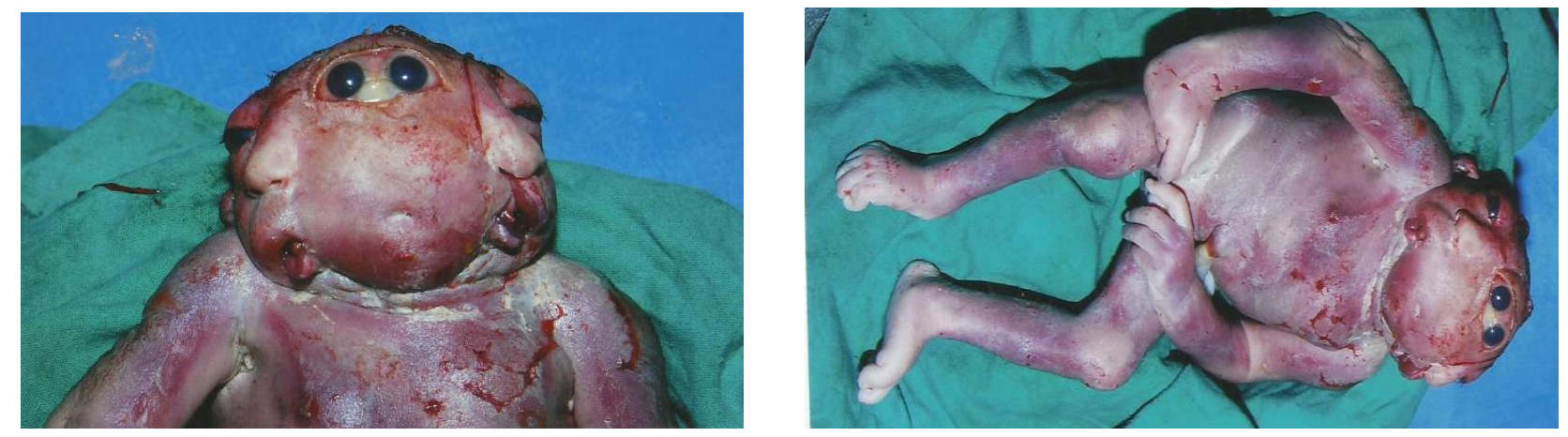

Fig. 4: Dipro1

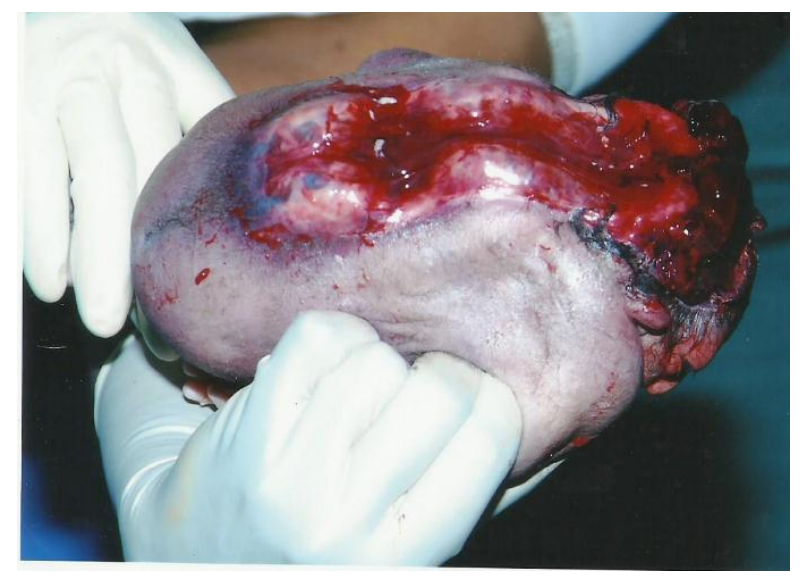

Fig. 5: Dipro2

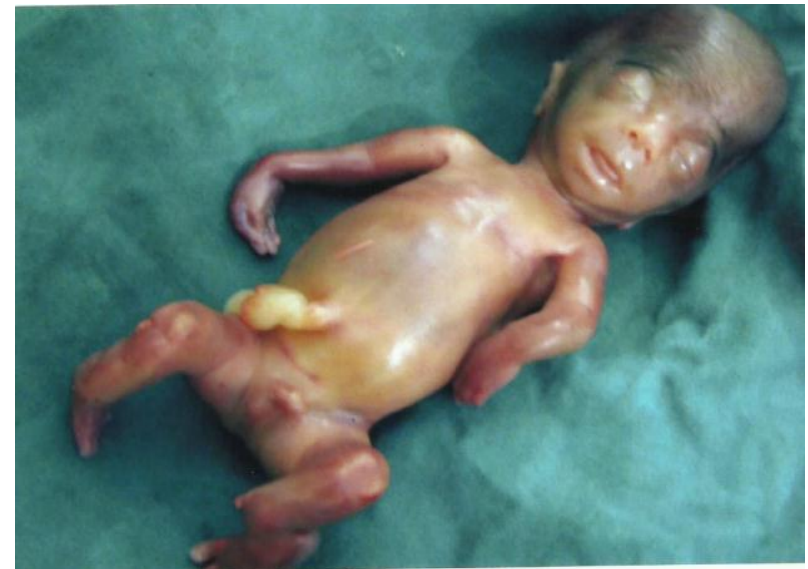

Fig. 6: Echondroplacia1

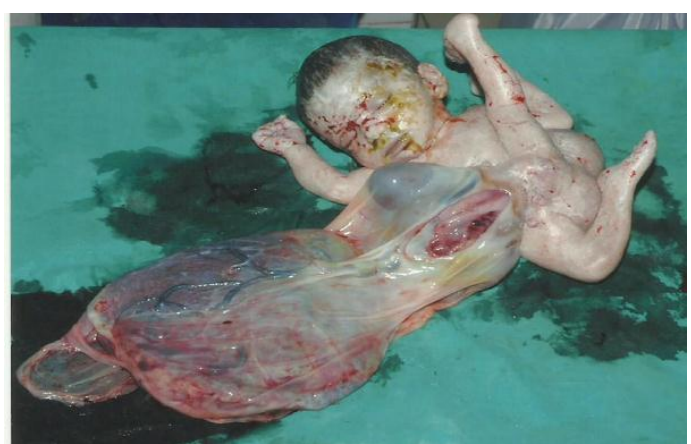

Fig. 7: Gastro1 


\section{ORIGINAL ARTICLE}
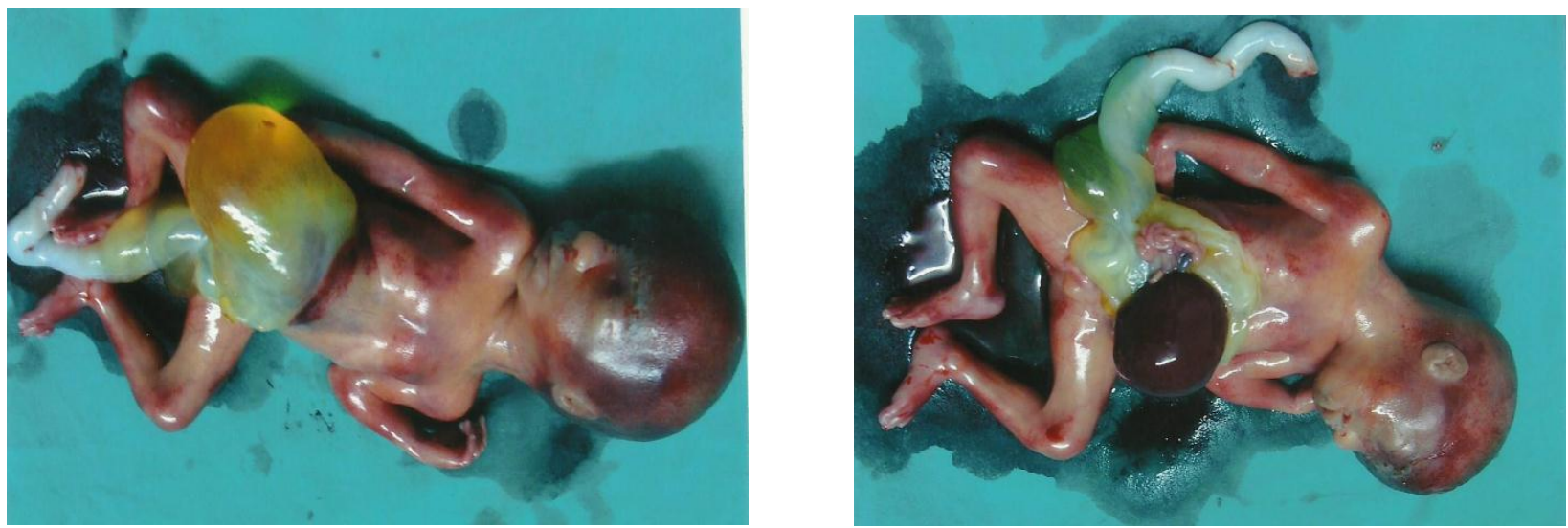

Fig. 8: Ophelaci1
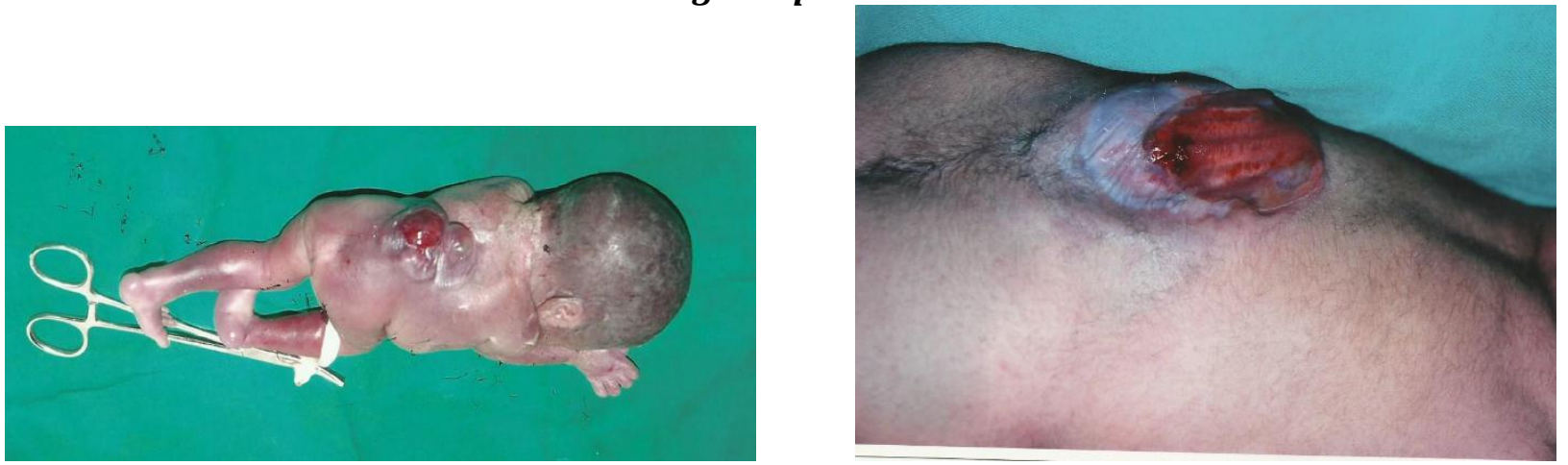

Fig. 9: Spi bifida1
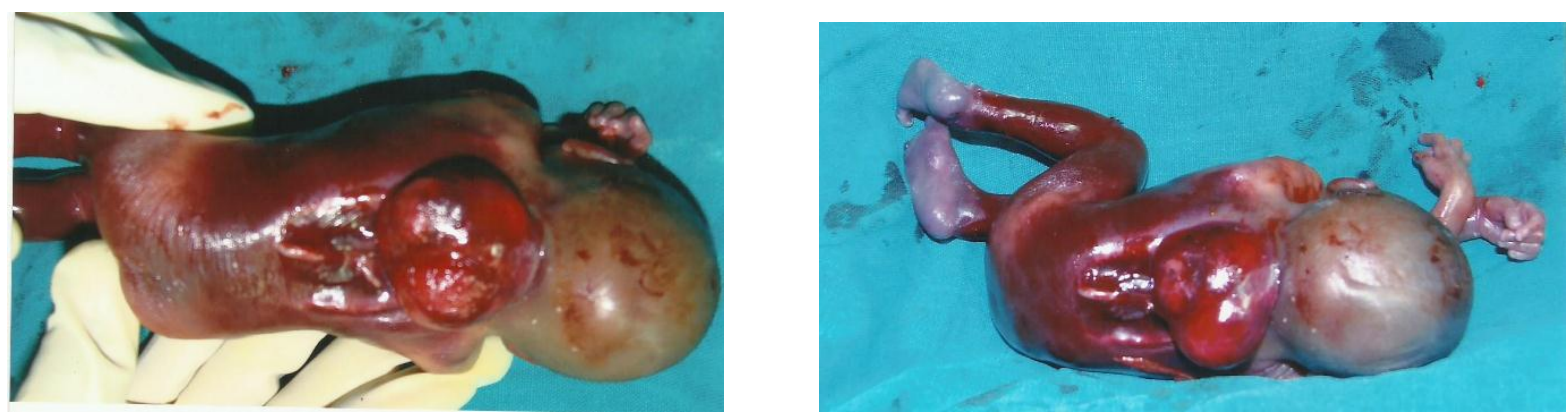

Fig. 10: Spi Dm1

CONCLUSION: Antenatal diagnosis and fetal congenital anomalies is helpful is continuing normal pregnancies and terminating abnormal fetal anomalies thereby reducing infant morbidity and mortalities.

It also reduces the mental agony of the couple. Progressive improvements in ultrasound equipment have permitted in diagnostic capacity within the field of prenatal diagnosis of structural fetal anomalies

However the accuracy of ultra sound depends on the obtaining correct anatomic views and in differencing between normal and abnormal structures, gestational age of the fetus and the ultrasound machine. Recent introduction of and three dimensional and four dimensional ultrasound has produced more objectives and accurate information on fetal development. So ultrasound has made possible diagnosis of congenital anomalies and thereby intervention. 
In my practice, I have seen most of the abnormalities in a consanguineous couple.Most of the patients consult the gynecologist after 8 weeks of pregnancy who won't consume folic acid leading ti neural tract deformities. My final conclusion is Routine folic acid supplements to all woman expecting a pregnancy,

Routine ultrasound evaluation at various stages of pregnancy and timely termination of abnormal fetuses. Trying to avoid consanguineous marriages.

\section{REFERENCES:}

1. Borzabadi-Farahani A, Gross J, Sanchez-Lara PA, Yen SL. (2013). "An unusual accessory mandible and a submucosal cleft palate-a case report and review of the literature." Cleft Palate Craniofac J. 50 (3): 369-75. doi:10.1597/11-032.PMID 22404912.

2. Borzabadi-Farahani A, Yen SL, Francis C, Lara-Sanchez PA, Hammoudeh J. (2013). "A rare case of accessory maxilla and bilateral Tessier no. 7 clefts, a 10-year follow-up." J Craniomaxillofac Surg. 41 (6): 527-31. doi:10.1016/j.jcms.2012.11.019.PMID 23333494.

3. Kaneko, Kotaro J.; Kohn, Matthew J.; Liu, Chengyu; Depamphilis, Melvin L. (2007)."Transcription factor_TEAD2_is_involved_in_neural_tube_closure". Genesis 45 (9): 577-87. doi:10.1002/dvg.20330. PMC 2765819. PMID 17868131.

4. Cowchock, S.; Ainbender, E.; Prescott, G.; Crandall, B.; Lau, L.; Heller, R.; Muir, W. A.; Kloza, E. et al. (1980). "The recurrence risk for neural tube defects in the United States: A collaborative study". American Journal of Medical Genetics 5 (3): 309-14.doi:10.1002/ajmg.1320050314. PMID 7405962.

5. "Man_with_Almost_No_Brain_Has_Led_Normal_Life", Fox News (2007-07-25). Also see"Man_with tiny_brain_shocks_doctors", NewScientist.com (2007-07-20); "Tiny_Brain,_Normal_Life", ScienceDaily (2007-07-24).

6. "Man_Lives_Normal_Life_despite_Having_Abnormal_Brain". The Globe and Mail. July 19, 2007. Archived from the_original on August 28, 2007. Retrieved July 15, 2012.

7. Kanagawa SL, Begleiter ML, Ostlie DJ, Holcomb G, Drake W, Butler MG (2002). "Omphalocele_in three_generations_with_autosomal_dominant_transmission". J. Med. Genet. 39 (3): 184-5. doi:10.1136/jmg.39.3.184. PMC 1735073. PMID 11897819.

8. Yatsenko SA, Mendoza-Londono R, Belmont JW, Shaffer LG (2003). "Omphalocele in trisomy 3q: further delineation of phenotype". Clin. Genet. 64 (5): 404-13. doi:10.1034/j.13990004.2003.00159.x. PMID 14616763.

9. "In_Conversation_with_Medicine's_Miracle_Workers_--_Dr_Chumpon_Chan_and_Dr_Keith_Goh". Channel News Asia Singapore. April 19, 2001. Retrieved March 27, 2010.

10. "Siamese_twin_Jodie_to_go_home_soon'". BBC News. April 23, 2001. RetrievedMarch 27, 2010.

11. Kitoh H, Kitakoji T, Tsuchiya H, Katoh M, Ishiguro N (2007). "Distraction osteogenesis of the lower extremity in patients that have achondroplasia/hypochondroplasia treated with transplantation of culture-expanded bone marrow cells and platelet-rich plasma". J Pediatr Orthop 27 (6): 629-34. doi:10.1097/BP0.0b013e318093f523.PMID 17717461.

12. Vajo, Z; Francomano, CA; Wilkin, DJ (2000). "The molecular and genetic basis of fibroblast growth factor receptor 3 disorders: the achondroplasia family of skeletal dysplasias, Muenke craniosynostosis, and Crouzon syndrome with acanthosis nigricans.". Endocrine Reviews 21 (1): 23-39. doi:10.1210/er.21.1.23.PMID 10696568. 


\section{ORIGINAL ARTICLE}

\section{AUTHORS:}

1. B. Prathap Kumar

\section{PARTICULARS OF CONTRIBUTORS:}

1. HOD, Department of Radiology, Karpagam Medical College, Coimbatore.

FINANCIAL OR OTHER

COMPETING INTERESTS: None

\section{NAME ADDRESS EMAIL ID OF THE} CORRESPONDING AUTHOR:

Dr. B. Prathap Kumar,

HOD, Department of Radiology,

Staff Quarters,

Karpagam Medical College,

Coimbatore.

E-mail: pratap.karpagam682@gmail.com

Date of Submission: 09/02/2015.

Date of Peer Review: 10/02/2015.

Date of Acceptance: 16/10/2015.

Date of Publishing: 24/10/2015. 